\title{
Relevance of Real Options to Corporate Investment Decisions
}

\author{
Giampiero Favato*
}

'Real Options' is the term used to refer to the application of option pricing theory to the valuation of investments in non-financial or 'real' assets, where much of the value is attributable to flexibility and learning over time A key problem with real options is that there are many different approaches. In this paper, the different taxonomies that have been identified are reviewed, together with their implications for management use.

JEL Classification: G11, G15.

\begin{abstract}
$\mathrm{T}$ The term 'Real Options' was coined by Stewart Myers in 1977 and refers to the application of option pricing theory to the valuation of investments in non-financial or 'real' assets, where much of the value is attributable to flexibility and learning over time. This means that the opportunity inherent in a capital project can be viewed as implied contracts that allow management to choose only those actions that have positive cash flow effects. Where a difference arises, however, is that the underlying assets of the options in a capital investment decision are real assets like the development of a new plant, rather than financial assets, like stocks and shares. As a consequence, the options imbedded in the investment decisions are referred to as 'Real Options' as opposed to financial options.
\end{abstract}

Research undertaken in the last two decades has shown that managers in diverse fields tend to commit the same kind of decision-making mistakes. Of these, the single most common decision trap is what is referred to as 'frame blindness' - -setting out to solve the wrong problem because a mental framework has been created for a decision that causes the best option to be overlooked. In fact, the word 'option' is actually extremely relevant because in recent years practitioners and academics have argued that traditional discounted cash flow models do not capture the value of options embedded in many corporate decisions. These options need to be considered explicitly because their value can be substantial.

To date, options literature has had relatively little influence on management practices. Attention to real options has been scant, partly because modeling investments as options is a highly complex subject that is generally presented in a technical fashion. However, options have great potential relevance to managers, given that the manager's role is to use his/her skill to maximize the shareholders' wealth. Ownership and control of an investment project can often generate follow-on opportunities which are additional to the project's cash flows. For example, the purchase of a computer software company entitles the owner to the company's free cash flow,

\footnotetext{
* Academic Fellow, Henley Management College, School of Projects. Processes and Systems, UK. E-mail: giampiero.favato@henleymc.ac.uk
}

(C) 2008 The Icfai University Press. All Rights Reserved. 
but the assets acquired in place is not the only opportunity purchased. Along with the assets there may also be the chance to acquire less tangible benefits, for example, to learn about other software companies that might be for sale. The company may also include highly skilled individuals who could be used to produce extra at little cost, but with high value. Because such follow-on investment opportunities are relatively intangible and speculative, their expected cash flows are rarely examined directly. Nevertheless, these opportunities may have important value.

A key problem with this approach to real options is that it is only one view and there are numerous different approaches. An attempt to provide some taxonomic order to the plethora of real option models available would probably help to make real options real.

\section{Taxonomy Based on Management Investment Choices}

Trigeorgis (1993) identified the six most common categories of real options:

1. Option to defer is the right to postpone an investment in order to benefit from the resolution of uncertainty.

2. Option to scale up/down is the right to alter operating scale when market conditions change.

3. Option to abandon is the right to cancel further investments in a project in order to avoid incremental costs or to realize the project's salvage value.

4. Time to build option: Each stage of the investment can be seen as an option on the value of the subsequent stages, hence the option can be valued as a compound option (option on option).

5. Switch option is the choice of alternative use of the project's assets if they have more than one possible application.

6. Growth/strategic option: Investment opportunities that arise in the future by undertaking the project, but they are constituent of the initial project.

Copeland and Keenan (1998) further simplify the impact of uncertainty on managerial investment decisions:

a) Option to Invest/Grow:

- Scale-up: Early entrants can scale-up through cost-effective sequential investments as the market grows (economies of scale growth options and start-up options).

- Switch-up: Speedy commitments in the first generation of product/technology give preferential position to companies to switch over to the next generation (market power).

- Scope-up: Investments in proprietary assets in one industry may enable companies to enter another sector simultaneously and cost-effectively (economies of scope).

b) Option to Defer/Learn: Companies can delay investment until more information or new competencies are acquired (deferral option). 


\section{c) Option to Divest/Shrink:}

- Scale-down: Companies can reduce the investment on a project if new information changes the expected payoffs; at its extreme, it includes shutdown.

- Switch-down: Companies can switch to more cost-effective and flexible assets as new information/technology are available.

- Scope-down: Companies can limit the scope of their operations when there is no marginal potential in the business opportunity; at its extreme, it would include the abandonment option.

The option identification and qualification process represents a unique learning opportunity for management. Rather than ignoring the future flexibility as an integral part of the project's financial valuation, management has to focus on it explicitly, proactively planning on how to protect and to expand the project's value in the context of the uncertainty it is likely to face.

\section{Taxonomy Based on Pricing Models}

Damodaran (2002) relied on calculus complexity to identify two fundamental models for valuing options:

1. The Discrete-Time Model: It assumes that the time to expiration can be divided into a number of subintervals (the so-called nodes), in each of which only two possible values are allowed. This means that, compared to the asset value today, $(V)$ the value of the asset will either increase to $V_{\text {up }}$ with the probability $p$, or it will decrease to $V_{\text {down }}$ with the probability

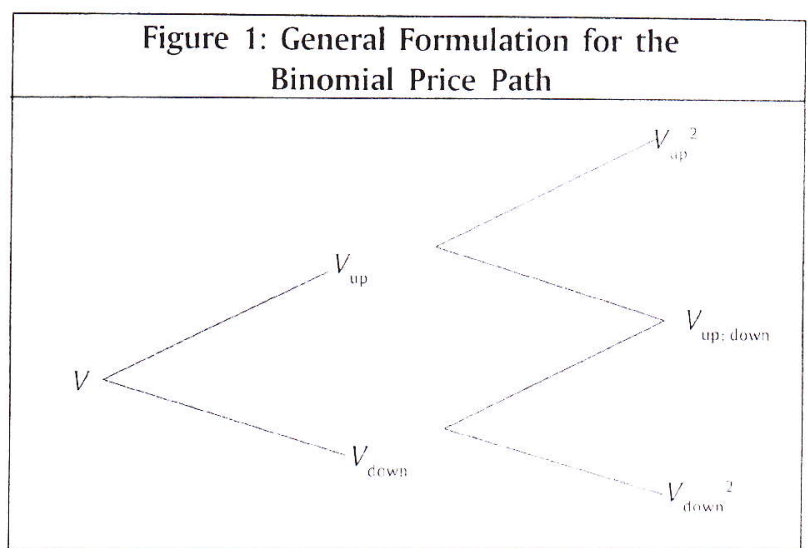
$1-p$. This is illustrated in Figure 1 , showing the general formulation for the binomial price path, in which two intervals (nodes) are considered.

2. The Continuous Model: While the discrete-time model provides an intuitive feel for the determination of option value, it requires a large number of inputs, in terms of expected future prices at each node. It also implies discrete asset price movements,

including a time interval ( $t$ ) between movements. As $t$ approaches 0 , price changes become smaller, the limiting distribution is the normal distribution and the price process is a continuous one. The continuous model explicitly assumes that the price difference between the two nodes can be infinitely small, following a normal distribution. The value of an option according to Black-Scholes (B-S) can be written as a function of the following variables: 
Project Value : Estimated net present value

Exercise Price : Cost of the project's assets

Time : Time to expiration of the option

Volatility : Estimated variance of project value

Opportunity Cost : Riskless interest rate

Mun (2002) further subdivided the plethora of continuous models which could in principle be applied to real option evaluation into four mainstream methods:

1. Closed-Form Solutions: Models like the B-S, where there exists equations that can be solved given a set of geometric Brownian motion assumptions.

2. Lattices (Binomial and Trinomial Models): Lattices break down the time to expiration into very large number of intervals or steps. At each step it is assumed that the asset's value will move up or down by an amount calculated using the volatility and time to expiration. This produces a binomial/trinomial distribution of underlying asset values, Lattices basically solve the same equation using a computational procedure, that the B-S model solves using an analytic approach.

3. Finite Difference Method: It values the option by solving the relative partial differential equation numerically. The partial differential equation is first approximated by a set of difference equations, which are then solved iteratively from the known boundary conditions.

4. Monte Carlo or Quasi-Monte Carlo Path-Dependent Simulations: The distribution(s) used to generate returns on the underlying asset(s) need not have closed form analytic expression, thus opening the possibility of deriving prices using random distributions.

\section{Taxonomy Based on Valuation Approach}

Borison (2005) proposed a classification of real options based on their underlying valuation approach:

- The Classic Approach (No Arbitrage, Market Data): This approach represents the direct application of classic option pricing from finance theory to non-financial or real investments, based on the existence of a traded replicating portfolio, and building on data drawn from that portfolio to develop option values. It assumes that capital markets are complete, and therefore all corporate investments are equivalent in the capital markets and can be effectively hedged through this traded replicating (tracking) portfolio.

- The Subjective Approach (No Arbitrage, Subjective Data): This approach is based on the existence of a traded replicating portfolio, but built on data that is subjectively assessed (although the use of this data is not explicitly justified).

- The Marketed Asset Disclaimer (MAD) Approach (Equilibrium-based, Subjective Data): This approach does not rely on the existence of a traded replicating portfolio, but the same assumptions used to justify the application of net present value (or discounted cash flow) to capital investments are used to justify the application of real options analysis. 
- The Revised Classic Approach (Two Investment Types): The three foregoing approaches are all examples of alternative 'one-size-fits-all' views. Their proponents argue that they are applicable in the same basic fashion to all types of corporate investments. The revised classic approach, on the other hand, is based on the view that there are two different types of corporate investments, each requiring its own approach. In particular, real options analysis should be used when investments are dominated by market-priced or public risks, and dynamic programming/decision analysis should be used when investments are dominated by corporate-specific or private risks.

- The Integrated Approach (Two Risk Types): The four approaches described so far originated with practitioners in finance looking to expand to real as opposed to financial investments. The integrated approach, on the other hand, originated with practitioners in management science looking to incorporate capital market considerations, and shareholder value in particular, into their evaluation of corporate strategy. The integrated approach begins by recognizing two types of risk associated with most corporate investments-public (or market) and private (or corporate). But unlike the classic or revised classic approaches, the integrated approach neither views private lisk as a source of error (as does the former) nor does it assign investments entirely to one of the two categories (as does the latter). Instead, it acknowledges that most investment problems encountered in practice have both kinds of risk and it is designed to address that very situation.

\section{Real Options are Still Unpopular Among Business Practitioners}

Although the general concept of real options is clear, their specific benefits for individual investment decisions are not. Options are still an obscure mathematical tool and the partial differential equation at the core of the option pricing model leaves management with a blank face. The complexity of the stochastic calculus prevents practitioners to see the new 'decision space' created by real options and to move inside this space at ease.

The development of the classical Black and Scholes equation probably did not help executives to make real options real. Academicians felt that the early attempts to apply real options to the business world had been too simplistic to reflect the complexity of actual investment decisions. Theoretical research took the direction of searching for more 'realistic' statistical models, increasing the complexity of calculus instead of focusing on management relevance. A number of sophisticated models were rapidly introduced, ranging from binomial lattices to exotic options. Fundamentally, over the years, real options never left the territory of fancy mathematics to move onto the desk of management practitioners.

The quest for statistical precision reached its paradox in 2002, when Mun observed that in the limit, results obtained with the use of fancy binomial lattices tended to approach those derived from the Black and Scholes model. To prove that, the author performed a 10,000 simulation test, making approximately $5 \times 109$ nodal calculations. This daunting task was equivalent to 299 Excel spreadsheets or $4.6 \mathrm{~GB}$ of computer memory.

Probably the real paradox was to try and help the managers to understand the intricacy of a difficult mathematical model by using even more obscure levels of calculus. If the original Black and Scholes equation has not been used so far because it was difficult to understand, what are 
the chances that management will ever use a quasi-Monte Carlo American binomial lattice or a discrete up-and-in barrier option model? Is the sophisticated calculus even relevant to real options-based decisions? What is actually relevant to the management in making an investment decision? How real options can become a relevant evaluation tool in the hands of business executives?

\section{Thinking about Real Options as a Videogame}

To answer these questions we should rethink the entire development of real options research, taking a completely new direction inspired to the unique goal of achieving relevance in the management's eyes.

Providing a graphical representation of the Ito's lemma, the partial differential equation central to the Black and Scholes pricing model, would possibly help practitioners to visually capture the essence of real option thinking. What if Black and Scholes had invented a videogame rather than a financial evaluation tool? The hypothesis is provocative, but not without foundation. Actually at the beginning of the 1970s, at the same time as Black and Scholes, and Merton were applying the newly available computational capabilities to derivative pricing, software engineers were having some fun using basic programming language to create the first console games for television. The first tennis game, 'Odyssey', was actually released in 1972, one year before the first real options publication.

How different would have been the development of real options if they had been originally designed as a videogame? First of all, real options would have been graphical.

The authors imagined a simple dynamic visualization of the original Black and Scholes replicating portfolio, where the option value comes as the result of a basic game for television, not dissimilar from the first arcade game (Figure 2). The essence of real option thinking jumps out of the screen as an immediate visual experience, maintaining intact the rigor of its logical and mathematical foundations. The actual graphical expression of Black and Scholes partial differential equation is protected by copyright and it will be a core component of the paper.

At first the basic videogame would have been received as an amazing innovation and a lot of fun for the home games fanatics. For the first time this basic game would allow to interact with the television set, making the viewer an active player of the game, rather than a passive recipient of television programs. This enthusiastic acceptance would have been no different from the original expectations originated by real option thinking. While cash flow discounting substantially ignored any active management influence on the value of an investment projecting into the future, real options valued the possibility (option) to change direction at a later date. Rather than passively looking at the television, now management was able to be a player and to make its own game.

The original Black and Scholes game was simple, fairly intuitive and did not require specific skills: anybody who owned a television set could immediately play and have fun. But it never had the chance to become really popular. Keeping pace with the development of a new technology, the personal computer, it soon became boring and obsolete. The new generation of computer geeks soon realized that the game was too simplistic to reflect reality; the new 


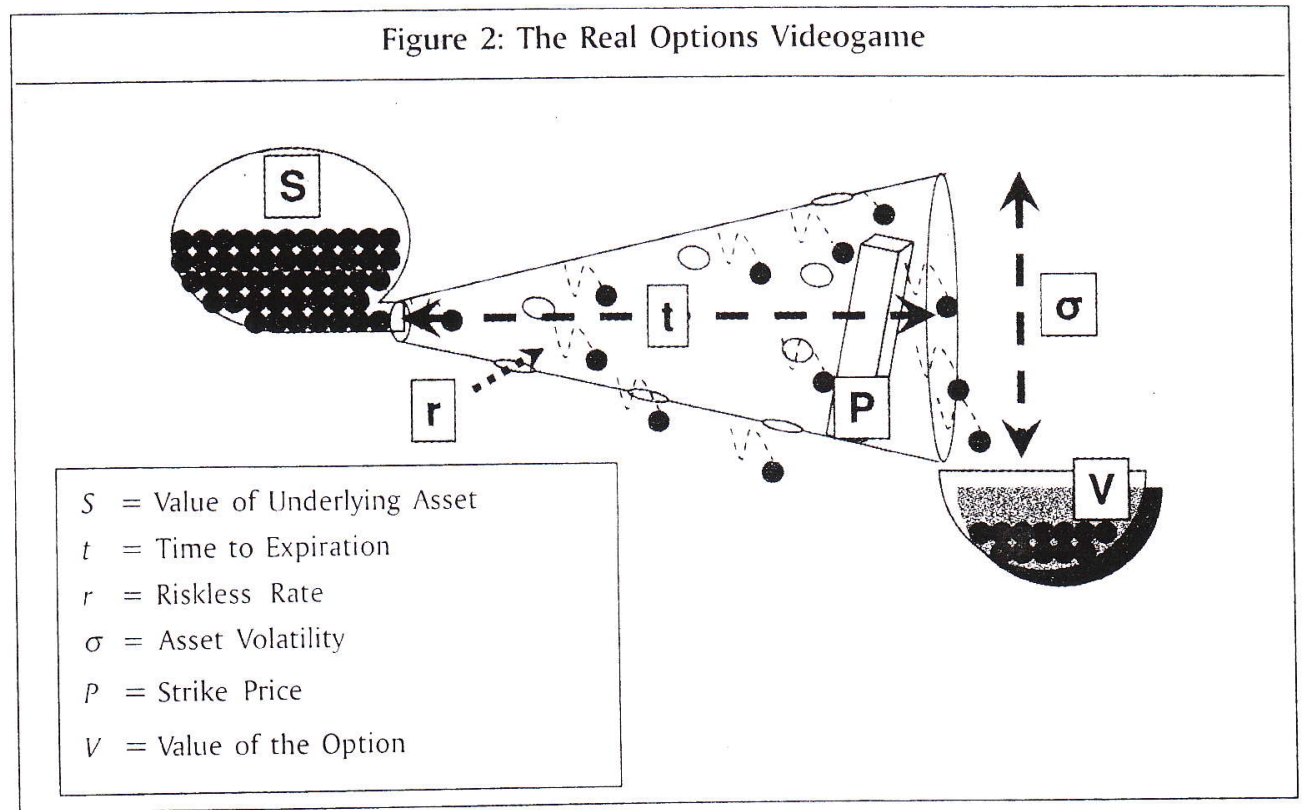

computational capability now available could run far more sophisticated 'reality games'. A number of software releases were developed based on the original Black and Scholes simple game for video console. The new games were highly graphical, more exciting and with progressive levels of challenge. They also required complicated set up procedures, some level of programming skills and bigger and bigger computers. The new games were fascinating, but difficult to play: every single computer key operated a different command and the setup was so exhausting that it spoiled the fun of the amazing new graphics.

Videogames became the pass-time of a restricted elite of computer nerds, who could spend the night figuring out the way to proceed to the next level of the game. Realism was obtained at the expense of simplicity. Common people did not even understand the gist of the new games and they felt that they were simply too difficult to play with, to have fun with them.

The new level of complexity was not relevant to their entertainment needs. Once again, the mechanistic development of real options pricing models did not differ at all from the development of computer games. Supported by increasingly larger computational capabilities, the academic community focused on high math to develop new generations of sophisticated real option pricing models. The attempt to capture the complexity of real investment decisions with mathematical calculus could be defined as the quest for the ultimate silver bullet. But instead of improving the quality of investment decisions, the high math trend of financial research probably scared management away. The new models are too complex to be deeply understood by executives with a large diversity of cultural backgrounds. They do not have time to appreciate the nuances of sophisticated statistical scenarios. Common experience is that the investment decisions spanning over long time periods are influenced by many factors unknown at present, so managers are not overly concerned by the false precision, but what they really 
need is a flexible valuation tool, easy to understand and to be played with at any time after the decision is made, when new information become available and the investment scenario consequently changes. Management did not have the possibility to fully understand and put into practice the initial Black and Scholes model; the chances that they will use the more sophisticated models based on the concept, which is still unclear are actually marginal. Real options thinking should be developed towards the direction to make its core concept accessible and relevant to everybody.

\section{Real Options for PlayStation}

The same revolutionary direction was impressed by Sony in the development of videogames with the introduction of PlayStation, that is, to transform computer games into home entertainment that everybody could enjoy. To achieve this breakthrough development of an existing technology, Sony redefined the concept of relevance in videogames programming, reinterpreting it from the perspective of the player. To really enjoy a game, the players wanted amazing graphics, hassle-free setup and simple commands to immediately play and enjoy the game itself.

To make this possible, Sony made the decision that all games for PlayStation could be initially played using only four keys. All other commands and setup choices could be grouped into pull-down menus, because they are not relevant to play the essential game, while they can still be useful in more advanced stages.

The success of PlayStation was unprecedented. Sony sold over 70 million consoles to an incredibly diverse customer base, becoming a cult for players of all ages and from different cultural and educational background. The key to success was its redefined concept of relevance. The authors imagined what it would take to play the Black and Scholes videogame with the PlayStation.

First of all, the PlayStation version of the classic Black and Scholes game should be played using only the four main command keys. The authors identified the four parameters most relevant to the determination of real option value, among the possible choices-the selection of the most appropriate real option pricing model, the asset price, the strike price, market volatility, time to expiration and risk-free rate. To choose the four main command keys, the authors needed to provide answers to a series of questions:

- How much would the option value change by use of different pricing models?

- What is the option value sensitivity to each of the fundamental parameters common to all the models?

- Are the chosen four main command keys sensitive enough to command the game?

To avoid selection biases, the authors used a published investment decision business case, related to the pharmaceutical industry. A biotech company must decide whether to continue the development of a drug in late clinical stage of development. All the fundamental parameters for real option evaluation are given. Which are the most relevant drivers of the development option? 
Calculated with the classical Black and Scholes model, the resulting option value was $\$ 3.9 \mathrm{mn}$. The key parameters were input into 12 different real option spreadsheets, including European and American lattices and exotic models.

The convergence of option values resulting from such a variety of calculus was surprising. The choice of the real option model had a very limited impact on the option value. As the distribution of outcomes did not fundamentally violate normality, $95 \%$ of the times the option values calculated with all the 13 models fell into plus or minus two percentage points from the mean value. The difference was statistically significant, but is it relevant from the management perspective?

To answer this fundamental question, the authors proceeded to test the sensitivity to main real option parameters in all the 13 models used to calculate the option value. The impact on option value of a one percent change in each main parameter calculated separately was compared to the value calculated with the Black and Scholes model, which was considered as the base case.

All 13 models behaved very consistently and the correlation between the paired outcomes of the sensitivity analysis for all the models was significant. The outcomes grouped by each single pricing model were also normally distributed.

The statistical robustness of the sensitivity analysis allowed comparing the median impact of one percent change in the main parameters on the resulting option value. Changes in the expected asset value, strike price, market volatility and time to expiration determined a significantly greater impact on the option value compared to risk-free rate and choice of the real option model.

Therefore, the four main command keys of the real option game for PlayStation should be: asset value, strike price, volatility and time to expiration. Both the choice of risk-free rate and pricing model should go into the setup menu.

It is still important, though, to briefly point out the most relevant managerial take away of this entire research effort: the option value is much more influenced by the case parameters than by the choice of the pricing model. The accuracy of an investment decision depends more on the quality of the fundamental inputs, such as the future expected value of the project, the cost of the option (strike price), the changes in the market (volatility) and the length of time available to postpone the decision (time to expiration), than on the complexity of calculus used to assess the project. Spending time on the evaluation of these four parameters is actually more important than choosing any sophisticated pricing tool. Continuously monitoring the evolution of the main parameters and their relative changes compared to the initial assumptions is the fundamental driver of real option value. In extreme summary, the real option version for PlayStation creates value by allowing the player to focus on investment fundamentals-always keep the eyes on the ball and control the game.

The authors also came up with a graphical representation of how to control the game by just using the four main command keys, showing the action of each command on the basic game.

Relevance of Real Options to Corporate Investment Decisions 
The last question left to answer was if the four main controls were sensitive enough to command the actual speed of the game. In other words, how easy is to make one percent error, the chosen threshold for the sensitivity analysis, in real life? The authors chose the most critical variable, the future value of the project, to answer the question-Was one percent error in forecasting frequent and relevant in pharmaceuticals? On a real sample of 42 drugs, whose sales were projected to a three year outlook, the average forecasting error versus actual sales was $4.4 \%$ in the first year, $9.1 \%$ in the second year, and almost $22 \%$ in the third year. Looking at each individual estimate, $80 \%$ of the times the single forecast error was larger than $5 \%$. The selected four main commands were probably sensitive enough to command a real life investment game.

In brief, the newly released game for PlayStation would possibly facilitate the adoption of real options by management executives, allowing the player to start playing immediately and to control the game using just the four main drivers of value.

\section{Testing the Game: A Biotech Case}

Original research was conducted to demonstrate the relative impact of the choice of any real option continuous pricing model compared to the sensitivity to fundamental inputs of the option value. To avoid methodological bias, the authors used a biotechnology business case by Villiger and Bogdan (2005). The case was related to a stop/go development decision of an experimental drug at the beginning of its clinical phase of development (Phase III).

\subsection{Inputs to the Model}

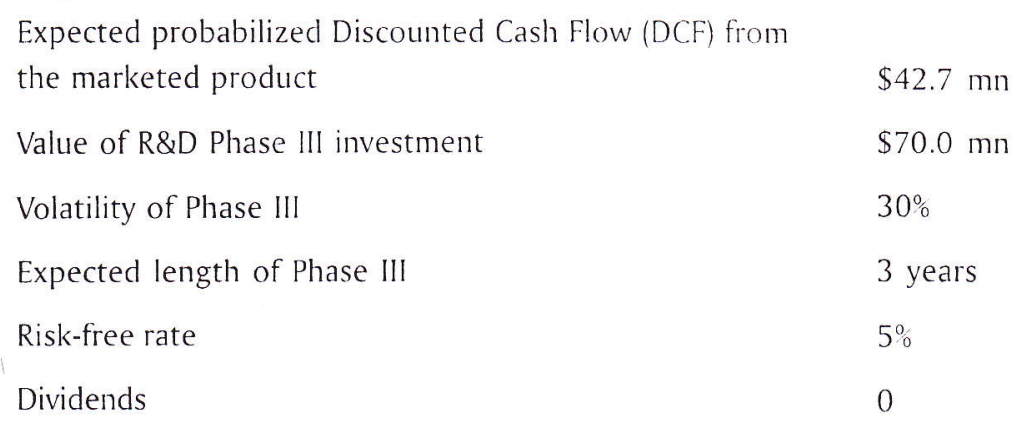

\subsection{Methodology}

The authors input the above data in 13 different real option continuous pricing models. The models included European options, American options and Exotic options.

\subsection{Results}

A set of 13 option values was obtained (Table 1).

The price distribution did not fundamentally violate normality, although both skewness -1.352) and kurtosis (2.618) values indicated a certain difference from central tendency. 


\begin{tabular}{|l|c|}
\hline \multicolumn{2}{|c|}{ Table 1: Option Values } \\
\hline Option Pricing Models & Value of the Call \\
\hline European BS with no dividends & 3.9357 \\
\hline European BS Monte Carlo & 3.9012 \\
\hline European BS Quasi-Monte Carlo & 3.8862 \\
\hline European Binomial (100 steps) & 3.9394 \\
\hline European Trinomial (100 steps) & 3.9412 \\
\hline Jump Diffusion (1 jump) & 3.8896 \\
\hline Jump Diffusion (2 jumps) & 3.9147 \\
\hline Jump Diffusion (3 jumps) & 3.9233 \\
\hline American Binomial & 3.9390 \\
\hline American Trinomial & 3.9412 \\
\hline American Finite Difference & 3.9409 \\
\hline Exotic Up-and-In (Continuous) & 3.9726 \\
\hline Exotic Up-and-In (Discrete) & 3.8247 \\
\hline Mean & 3.9192 \\
\hline Standard Deviation & 0.037215 \\
\hline
\end{tabular}

95\% of the times, option prices calculated with the 13 models would fall in between two standard deviation points (0.037215) from the mean value (3.9192). In other words, the choice of the model had a $+1-2 \%$ impact on the option value.

The t-test of the sample (379.712 - sig 0.000) confirmed that the sample prices difference from the mean is statistically significant.

\subsection{Discussion}

A $2 \%$ difference may be statistically significant, but is it relevant from the management point of view? To answer this question, the authors proceeded to verify the sensitivity of all the 13 models to inputs, calculating option prices for inputs changing one at a time by an interval of $1 \%$ (from $+5 \%$ to $-5 \%$ ). These values were the compared to the ones obtained from the base case, to measure the magnitude of difference. All 13 models behaved very consistently. The correlation between the sensitivity paired outcomes for all models was always very high, with the exception of the models based on Monte Carlo simulations, which showed a lower degree of correlation, but always significant at different levels, with just one exception. The correlation table provided additional evidence that all models move in synchrony, and their outcomes were concordant.

As it was demonstrated that all option pricing models outcomes by input change were correlated, the regression slope would define the sensitivity to each variable. The authors selected the American binomial model as a base case, as it better reflected the decision tree often used in pharmaceutical $R \& D$. The linear equations related to percent change of each single input are presented in Table 2. 


\begin{tabular}{|l|c|c|}
\hline \multicolumn{2}{|c|}{ Table 2: Linear Equations Related to Percent Change of Each Single Input } \\
\hline Value of the Asset & $y=14.942 x+3.952$ & $R^{2}: 0.999$ \\
\hline Option Price & $y=-11.043 x+3.951$ & $R^{2}: 0.998$ \\
\hline Volatility & $y=8.578 x+3.3937$ & $R^{2}: 1.000$ \\
\hline Time to Expiration & $y=5.919 x+3.3938$ & $R^{2}: 1.000$ \\
\hline Risk-free Rate & $y=1.605 x+3.9400$ & $R^{2}: 1.000$ \\
\hline
\end{tabular}

Therefore, $1 \%$ change in inputs would have the following impact on the base case option price $(\$ 42.7 \mathrm{mn})$ :

$$
\begin{aligned}
& +1 \% \text { Value of the Asset } \\
& +1 \% \text { Option Price } \\
& +1 \% \text { Volatility } \\
& +1 \% \text { Time } \\
& +1 \% \text { Rate }
\end{aligned}
$$$$
+0.14942
$$$$
-0.11403
$$$$
3.50 \%
$$$$
+0.85780
$$$$
-2.59 \%
$$$$
+0.59190
$$$$
2.01 \%
$$$$
+0.16050
$$

$0.38^{\circ}$

The choice of real option pricing model had a lower impact $(+1-2 \%)$ than a $1 \%$ change in future value of the asset, option price and volatility, a $2 \%$ change in time to expiration and a $5.5 \%$ change in risk-free rate. How frequent would there be a one percent error in real business life? The authors analyzed a database of 42 pharmaceutical products, whose sales were projected to a three year outlook. All products were already in the market when the forecast was prepared, which makes the case much easier than estimating the future value of a Phase III stop/go decision. Yet, the average forecast error on all products compared to actual sales was $+4.4 \%$ in the first year, $-9.1 \%$ in the second year, and +21.9 in the third year. Looking at a subgroup of 14 promoted products, which should have received more management attention, only five times the forecast error was lower than $5 \%(12 \%$ of cases). The impact of a more than $5 \%$ error in the estimate of future value would have been equivalent to a more than $20 \%$ error in option price. So, $80 \%$ of the times, the error in just one input of the model could have been ten times more relevant than the choice of the real option pricing model. $\widehat{ }$

\section{Bibliography}

1. Amram M and Kulatilaka N (1999), Real Options: Managing Strategic Investment in an Uncertain World, Harvard Business School Press, Boston, MA.

2. Amram M and Kulatilaka N (2000), "Strategy and Shareholder Value Creation: The Real Options Frontier", Journal of Applied Corporate Finance, Vol. 15, No. 2, pp. 15-28.

3. Black F and Scholes M (1973), "Application of Options and Corporate Liabilities", Journal of Political Econony, Vol. 81, No. 3. pp. 637-654.

4. Borison A (2005), "Real Option Analvsis: Where Are the Emperor's Clothes?", Journal of Applied Corporate Finance, Vol. 17. vo. 2. pp. 17-31 
5. Cheung J K (1993), "Managerial Flexibility in Capital Investment Decisions: Insight from the Real-Options Literature", Vol. 12, pp. 29-66.

6. Copeland T E and Antikarov V (2001), Real Options: A Practitioner's Guide. Texere, New York.

7. Copeland TE and Antikarov V (2005), "Real Options: Meeting the Georgetown Challenge", Journal of Applied Corporate Finance, Vol. 17, No. 2, pp. 32-51.

8. Copeland T E and Keenan P T (1998), "How Much is Flexibility Worth?", The McKinsey Quarterly, Vol. 2, pp. 38-49.

9. Damodaran A (2002), Investment Valuation: Tools and Techniques for Determining the Value of Any Asset, $2^{\text {nd }}$ Edition, Wiley \& Sons, New York.

10. Dixit A and Pindyck R (1994), Investment Under Uncertainty, Princeton University Press, Princeton, New Jersey.

11. Favato G, Mills R W and Weinstein B (2005), "Real Options Taxonomies", Henley Management College Discussion Paper Series HDP 10.

12. Luehrman T (1997), "What's it Worth? A General Manager's Guide to Valuation", Harvard Business Review, May-June, pp. 132-142.

13. Luehrman T (1998), "Investment Opportunities as Real Options: Getting Started on the Numbers", Harvard Business Review, July-August, pp. 3-15.

14. Luehrman T (1998), "Strategy as a Portfolio of Real Options", Harvard Business Review, September-October, pp. 89-99.

15. Mun J (2002), Real Option Analysis: Tools and Techniques, Wiley \& Sons, New York.

16. Russo J E and Shoemaker J P H (1989), Decision Traps, Fireside Edition, New York.

17. Smith J and McCardle K (1998), "Valuing Oil Properties: Integrating Option Pricing and Decision Analysis Approaches", Operations Research, Vol. 46, No. 2, pp. 198-217.

18. Smith J and Nau R (1995), "Valuing Risky Projects: Option Pricing Theory and Decision Analysis", Management Science, Vol. 41, No. 5, pp. 795-816.

19. Trigeorgis L (1993), "Real Options and Interactions with Financial Flexibility", Financial Management, Vol. 22, No. 3, pp. 202-225.

20. Trigeorgis L, Micalizzi A and Favato G (1997), The Eli Lilly Case, EGEA SDA Bocconi.

21. Villiger R and Bogdan B (2005), "Getting Real About Valuations in Biotech", Nature Biotechnology, Vol. 23, No. 4, pp. 423-428.

Reference \# 40J-2008-07-05-01 